\title{
CENTRIFUGAL COMPRESSOR STAGE. VANELESS DIFFUSER PRELIMINARY DESIGN BY UNIVERSAL MODELING METHOD
}

\section{O. SOLOVYEVA, YU. GALERKIN, A. REKSTIN, K. SOLDATOVA, V. YUSHA \& K. KABALYK}

National Technology Initiative Center for Advanced Manufacturing Technologies based on the Institute of Advanced Manufacturing Technologies of Peter the Great St. Petersburg Polytechnic University Polytechnicheskaya, 29, St.Petersburg, Russia

National Technology Initiative Center for Advanced Manufacturing Technologies based on the Institute of Advanced Manufacturing Technologies of Peter the Great St. Petersburg Polytechnic University Polytechnicheskaya, 29, St.Petersburg, Russia

National Technology Initiative Center for Advanced Manufacturing Technologies based on the Institute of Advanced Manufacturing Technologies of Peter the Great St. Petersburg Polytechnic University Polytechnicheskaya, 29, St.Petersburg, Russia

Melbourn TU, Australia, Melbourne

Omsk State Technical University, Russia, Omsk, Russia

Lodz University of Technology, Institute of Turbomachinery Wolczanska 219/223 Lodz, Poland

ABSTRACT
Most often, industrial centrifugal compressors use two-section vaneless diffusers: a tapered inlet section and à constant-
width main section. The authors propose to choose such a width of the main section, at which the flow in the diffuser
remains non-separated at the surge limit. To implement the primary design method, an empirical equation of the
minimum non-separated flow angle versus the relative width of the diffuser, and the number of other equations are
proposed. The primary design of 18 stages in a practically important range of parameters was carried out, their
characteristics were calculated by the Universal modeling method and the sizes and flow angles were analyzed. The
method for calculating the diffuser dimensions is integrated into the Universal modeling method and is used in design
practice.
KEYWORDS: Design By Universal Modeling Method

Received: Jun 09, 2020; Accepted: Jun 29, 2020; Published: Sep 25, 2020; Paper Id.: IJMPERDJUN20201417

\section{INTRODUCTION}

$b$ - width of channel; $D$ - diameter; $h_{p}$ - polytropic head; $h_{T}$ - Euler head; $h_{w}$ - loss of head; $M_{u}$ - relative Mach number; $r$ - radius; $\operatorname{Re}_{b 2}$ - Reynolds number; $u$-blade velocity; $\alpha$ - flow angle; $\varepsilon$ - densities' ratio; $\Phi$-flow rate coefficient; $\varphi$ - flow coefficient; $\eta$ - efficiency; $\lambda_{c}$ - velocity coefficient; $v$ - divergence angle; $\psi_{T}$ - loading factor; $\psi_{T 0}$ - loading factor at zero flow rate; $\psi_{p}$ - polytropic coefficient; $\zeta$ - loss coefficient

\section{SUBSCRIPTS}

2 - Impeller outlet; 3 - diffuser inlet; 4 - diffuser outlet, des - design; cr - critical (at the surge limit), min - 
minimum

\section{OBJECT OF RESEARCH}

In the USSR, the system of views on process centrifugal compressor gas dynamics and the foundations of the gas dynamic design were formulated by the chief designer of the Nevsky plant in Leningrad (NZL) prof. V.F. Riess [15, 16, 17]. Priority was given to higher efficiency at nominal conditions and minimization of radial dimensions, therefore NZL and other manufacturers produced compressors with vane diffusers mainly. At the same time, vaneless diffusers have attracted the attention of researchers. The author of monographs $[10,11]$ used two different models with conflicting results for the analysis. An analogy with a straight-axis flat diffuser determined that the minimum loss coefficient corresponds to a certain flow angle in the VLD, at which the divergence angle of an equivalent flat diffuser is optimal. In the VLD of process compressors, the flow angle changes little along the radius; therefore, the equivalent divergence angle can be presented as:

$$
\operatorname{tg} \frac{v}{2}=\left(\frac{a_{2}-a_{1}}{l}\right)_{e c}=\frac{\sqrt{\frac{f_{2}}{\pi}}-\sqrt{\frac{f_{1}}{\pi}}}{\frac{r_{2}-r_{1}}{\sin \alpha}}=\frac{\sin ^{1,5} \alpha}{\sqrt{r_{2}}+\sqrt{r_{1}}} .
$$

In accordance with this concept, the optimal flow angle in the VLD is less than 900. Seemingly, it was confirmed by measurements of the total pressure at the VLD inlet at very little radial distance from the impeller (5\% of t6he impeller radius). The measured by this way characteristic of the loss coefficient really has a minimum. Figure 1 shows the result taken of the model stage test - model stage of the 20CE series of the Problem Laboratory of Compressor Engineering Leningrad Polytechnic Institute LPI (dashed line) [8, 23].

Figure 1 shows the flow rate coefficient $\Phi=0.055$, which is "optimal" for the VLD, corresponds to a flow angle of about 300. However, calculations by the same author $[10,11]$ using the boundary layer theory method showed that the loss coefficient of the VLD monotonically decreases with increasing flow angle in the VLD up to 900. Flow analysis and onedimensional calculations in [18] also showed that friction losses decrease and the flow's ability to resist separation in VLD increases with bigger flow angles. In VLD with $b(r)=$ const and $\alpha=$ const, the loss coefficient is (one-dimensional calculation):

$$
\zeta=\frac{\lambda}{4 \bar{b} \sin \alpha}\left(1-\frac{1}{\bar{D}_{4}}\right) .
$$

This way the optimal flow angle is 900 Figure 2.

Figure 2 shows Experimentally, the minimum of losses at $\alpha=900$ was confirmed by wind tunnel tests The initial flow circulation was created by the rotating grid system [29]. Investigation in [30] also supports correct understanding. The discrepancy reason between the VLD loss coefficient measured in the centrifugal stage and calculated one is evident. The impeller jet-wake losses occurs in VLD but these are not losses of a diffuser.

Calculations by formula (2) and alike show that the friction losses in a VLD with a width equal to the height of the 
impeller blades are less than in a diffuser with $b<b_{2}$. Although the flow angle increases while $b<b_{2}$ and the flow trajectory is shorter, the friction is bigger in narrower channel. However, VLD with $b>b_{2}$ can be used in low flow rate stages only with narrow VLD [22, 23]. In other cases, in expanding VLD flow angle decrease leads to flow separation, and rotating stall. Confirmatory experiments are presented in [13].

Thus, the logical solution is a classic vaneless diffuser with parallel walls and a distance between them equal to the height of the impeller blades. At the same time, extensive experiments of the Compressor Engineering Problem Laboratory back in the $1960 \mathrm{~s}$ [25] showed certain advantages of vaneless diffusers with an initial tapered section and parallel walls in the main section. Vaneless diffusers with a tapered initial section and the main section with $b_{3}=b_{4}$ are usual now $[8,12$, 18, 26] Figure 3:

The author $[14,19,20]$ proposed a mathematical model describing the reduction of mixing losses of the impeller in VLD tapered initial section. A noticeable effect of the tapered section of the VLD with $b<b_{2}$ on the impeller is recorded by direct measurement Figure 4.

Figure 4 shows the preliminary design task is to choose the correct ratio of the height of the impeller blades and the width of the main section of the VLD. The shape of the tapered section and the choice of the radial size of the VLD are the tasks of the subsequent stages of the design.

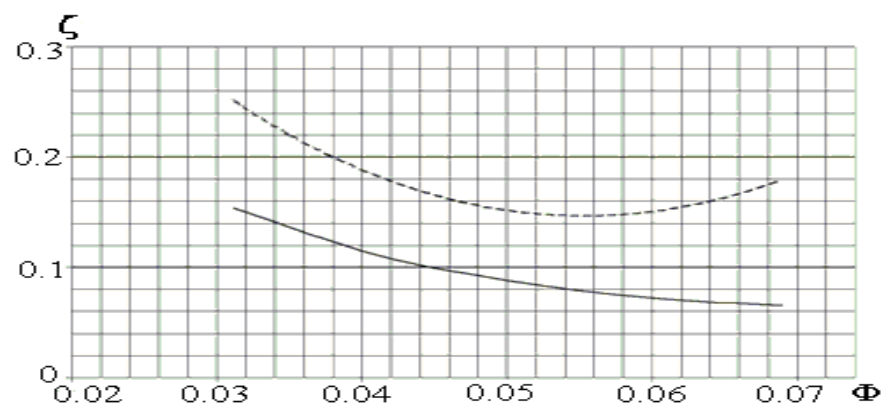

Figure 1: Loss Coefficient of a Vaneless Diffuser Versus Flow

Rate Coefficient $\left(\right.$ The Model Stage $\Phi_{\text {des }}=\mathbf{0 . 0 4 8}, \psi_{T \text { des }}$ $=0.48)$. (Dash Line - Measurement, Solid Line Universal Modeling Calculation).

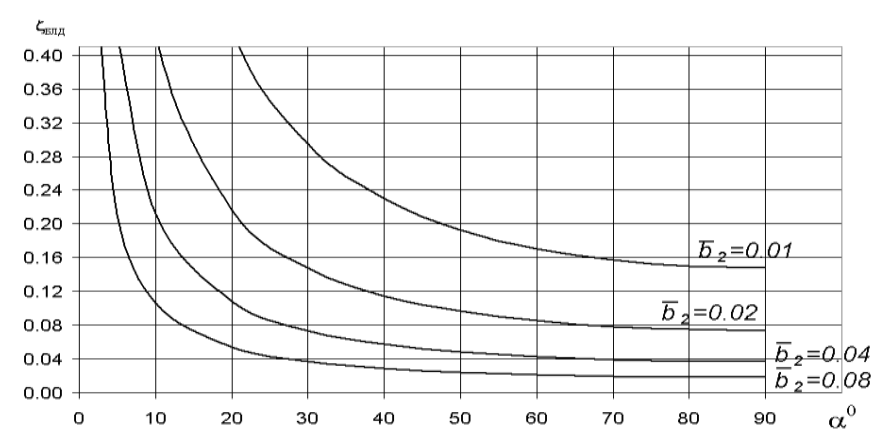

Figure 2: VLD Loss Coefficient Versus Flow Angle Ad

Different Relative Width, $D_{4} / D_{2}=1.65$ [18]. One-

Dimensional Calculation At Friction Coefficient $\lambda=0.015$. 




Figure 3: Typical Two-Section VLD With Tapered Initial Section.



Figure 4: Influence of the Initial Section of the VLD on the Impeller Work Coefficient: Circles - $b_{3} / b_{2}=\mathbf{1 , 0}=$ 1.0; Triangles - $b_{3} / b_{2}=\mathbf{1 , 0}=\mathbf{0 . 7 8 5}[16]$.

\section{THE PRINCIPLE OF VANELESS DIFFUSER PRELIMINARY DESIGN}

R\&D Laboratory "Gas Dynamics of Turbomachines" SPbPU is one of the leading centers for the research and design of compressors for various purposes: the reciprocating compressors [36 - 41], the rotary compressors [41 - 44], as well as turbo compressors $[3,5,21,28,45]$.

Laboratory scientists, the authors of [9] proposed the following principle for choosing the relative width of the VLD: after the preliminary design of the impeller, the exit flow angle is known. The VLD main section width must guarantee non-separation flow at surge limit. To find the width $\bar{b}_{3}$ is necessary:

- to determine the minimum flow angle ${ }^{\alpha_{3 \text { min }}}$ at which there is no separation in the VLD. This angle depends on the VLD width and similarity criteria,

- to determine the surge limit coefficient of the impeller, ratio,

- to find the angle of flow $\alpha_{2 c r}$ at the impeller exit at the surge flow rate,

- if in the VLD with $\bar{b}_{3}=\bar{b}_{2}$ the flow angle at the impeller surge limit $\alpha_{2 c r}$ is bigger than $\alpha_{3 \text { min }}$, the optimal VLD is $\bar{b}_{3}=\bar{b}_{2}$, 
- $\quad$ otherwise the width $\bar{b}_{3}<\bar{b}_{2}$ must be determined at which $\alpha_{3 c r}=\alpha_{3 \min }$.

\section{THE FLOW ANGLE AT WHICH SEPARATION STARTS}

The computational experiment with vaneless diffusers $[6,7,31]$ confirmed the known conditions under which the flow separation in the VLD occurs. Figure 5 shows meridian streamlines in VLD based on the of CFD calculations:

Figure 5 shows As in the experiments [18], the CFD calculation reveals separation on one of the walls. Figure 6 shows the change in the shear stress along the radius in the VLD $\bar{b}_{3}=0.057, \lambda_{c 2}=0.64, \alpha_{2}=100$.

Figure 6 shows The separation starts at the point with zero shear stress on the wall, as the theory of the boundary layer theory predicts. The shear stress is negative in the separation zone, since the flow moves in the opposite direction. Figure 7 shows the flow angles $\alpha_{\text {min }}$ at which separation starts in VLD with different relative widths in the investigated range of velocity coefficients and Reynolds numbers.

Figure 7 shows the flow angle $\alpha_{\text {min }}$ at which separation starts depends on the relative width of the VLD mainly. In narrow diffusers at $\bar{b}_{3}<0.029$, no separation was found. The shear stresses are higher in narrow passages. The influence of the Reynolds number in the investigated range was not found. The influence of the compressibility criterion is evident while $\bar{b}_{3}>0.08$ only.

Figure 8 shows the flow angles at the inlet at which the separation begins in the VLD $\bar{b}_{3}=0.029-0.10$ at angles $\alpha_{3}=10,15,20,25,30$ degrees. The values of the velocity coefficients $\lambda_{c 3}=0.39,0.64,0.82$.

The purpose of the calculations in $[6,7,31]$ was not to accurately determine the angle $\alpha_{\text {min }}$. To determine $\alpha_{\text {min }}$ calculations should be made with the angle step 10. Taking into account the large step of the flow angles at which the calculations in Figure 8 were carried out, the values $\alpha_{3 \min }=f\left(\bar{b}_{3}\right)$ can be considered independent of the velocity coefficients at $\bar{b}_{3} \geq 0.08$. In narrow VLD, separation was not detected at an angle $\alpha_{3} \geq 10^{\circ}$, but even at the surging boundary, the flow angle should not be less than 50. On this basis, an empirical formula was proposed:

$$
\alpha_{3 \min }=\operatorname{arctg}\left(0,0875+3,5 \bar{b}_{3}\right)
$$

A solid line in Figure 8 shows the function (3).

Figure 5: Meridian Streamlines In The VLD With

Relative Width $\bar{b}_{3}=\mathbf{0 . 1}, \mathbf{0 . 0 5 7}, 0.014[6,7,22]$.



Figure 6: The Shear Stress Along the Radius on the Walls Of The VLD $\bar{b}_{3}=\mathbf{0 . 0 5 7}, \lambda_{c 2}=\mathbf{0 . 6 4}, \alpha_{2}=\mathbf{1 0 0}$.

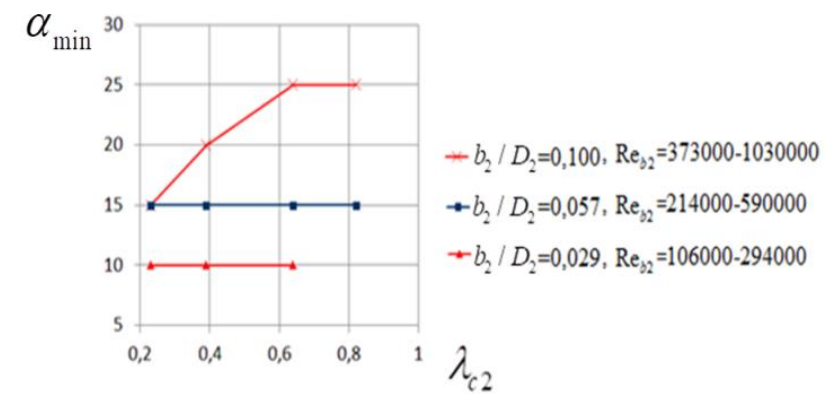

Figure 7: Flow Angles At Which Separation Starts In VLD With Relative Width $\bar{b}_{3}=\mathbf{0 . 1}, 0.057,0.029$,



Figure 8: Minimal "No Separation" Inlet Angle $\alpha_{\text {min }}$ Versus VLD Relative Width And Velocity Coefficient.

\section{ESTIMATION OF AN IMPELLER SURGE LIMIT}

The position of the surge limit is highly dependent on the impeller loading factor $\boldsymbol{\psi}_{\text {Tdes }}$. The higher the loading factor is, the more flat the pressure characteristic. As the flow rate decreases, the increase in losses is less compensated by the supply of mechanical work. With a further decrease in the flow rate, the exit pressure stops increasing, and surge occurs. The problem is discussed in detail in [2]. A simplified method is proposed for assessing the surge limit as a flow rate with a maximum pressure ratio. Such an understanding of the surge limit is generally accepted $[34,35]$. Below, the method for estimating the 
surge boundary from [9] is presented in a modified form.

The surge limit boundary corresponds to the flow rate at which the polytropic coefficient $h_{p} / u_{2}^{2}=\left(h_{T}-h_{w}\right) / u_{2}^{2}$ reaches its maximum:

$$
\frac{d\left(\psi_{p}\right)}{d \Phi}=0 .
$$

The linear dependence of the loading factor on the flowrate coefficient is analyzed in publications [0, 3]. Figure 9 shows proper head characteristic and the velocity triangle.
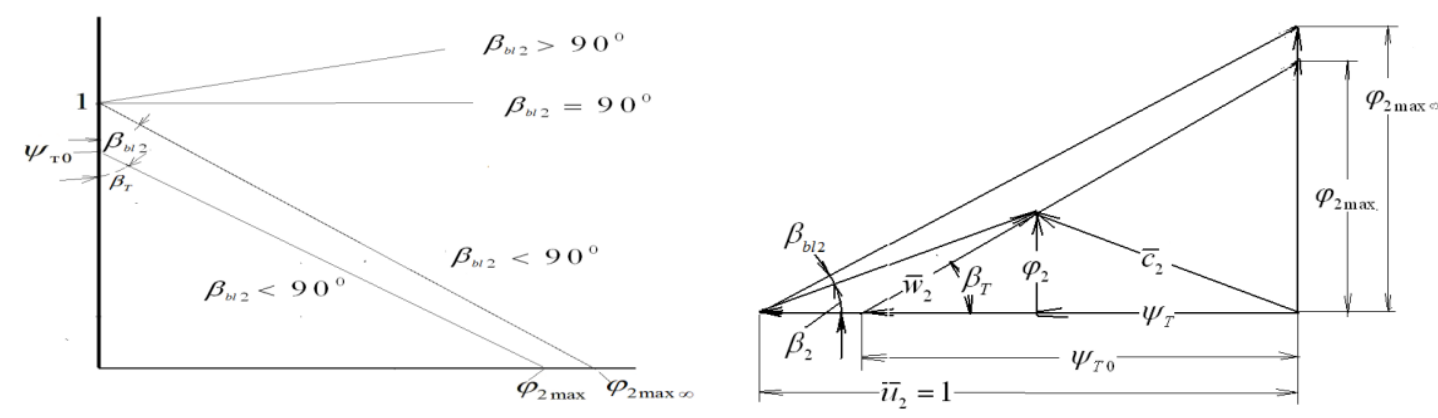

Figure 9: Loading Factor Characteristic and the Velocity Triangle With Linear $\psi_{T}=f\left(\varphi_{2}\right)$

[3].

Within the practically important part of the dimensional characteristics, the dependence of the pressure ratio on the flow rate is also linear, as indicated in the monograph [16]. Therefore, in modeling, it is customary to consider the function $\psi_{T}=f(\Phi)$ to be also linear:

$$
\psi_{T}=\psi_{T 0}-\left(\psi_{T 0}-\psi_{T d e s}\right) \frac{\Phi}{\Phi_{d e s}}
$$

The loading factor at zero flow rate depends on many factors, but the main tendency is that this coefficient is higher for impellers with large loading factor $\psi_{T \text { des }}$. Based on experimental data from publication [0], an approximate formula is proposed that is suitable for preliminary design purposes at $\psi_{T \text { des }}=0.40-0.70$ :

$$
\psi_{T 0}=0,84+0,27\left(\psi_{T d e s}-0,40\right)
$$

The relationship between polytropic and Euler heads can be represented as follows:

$$
h_{p}=h_{T}-h_{w d e s} \frac{h_{w}}{h_{w d e s}} .
$$

The following approximate expression is recommended for the ratio in [0]: 


$$
\frac{h_{w}}{h_{w d e s}}=1+8,5\left(1-\frac{\Phi}{\Phi_{d e s}}\right)^{3} .
$$

Meaning (8) the relation (7) is represented as:

$$
\psi_{p}=\psi_{T 0}-\frac{\psi_{T 0}-\psi_{T d e s}}{\Phi_{\text {des }}} \Phi-\psi_{T d e s}\left(1-\eta_{\text {des }}\right)\left[1+8,5\left(1-\frac{\Phi}{\Phi_{\text {des }}}\right)^{3}\right]
$$

Surge limit coefficient after differentiation (9):

$$
\frac{\Phi_{c r}}{\Phi_{d e s}}=1-\left[\frac{\frac{\psi_{T 0}}{\psi_{\text {Tes }}}-1}{17\left(1-\eta_{d e s}\right)}\right]^{0,5}
$$

\section{ANGLE OF FLOW OUT OF THE IMPELLER AT THE SURGE LIMIT. SELECTING THE WIDTH OF THE MAIN SECTION OF THE DIFFUSER}

The angle of flow out of the impeller at the surge limit is determined by the components of the velocity triangle. Flow rate coefficient at the impeller exit:

$$
\varphi_{2 c r} \approx \varphi_{2 d e s} \frac{\Phi_{c r}}{\Phi_{d e s}}
$$

Circumferential velocity component - loading factor $\psi_{T c r}$ :

$$
\psi_{T c r}=\psi_{T 0}-\left(\psi_{T 0}-\psi_{T c r}\right) \frac{\Phi_{c r}}{\Phi_{d e s}}
$$

Flow angle at the surge limit:

$$
\alpha_{2 c r}=\operatorname{arctg}\left[\frac{\varphi_{2 d e s} \frac{\Phi_{c r}}{\Phi_{d e s}}}{0.84+0.27\left(\psi_{T d e s}-0.40\right)-\left(0.84+0.27\left(\psi_{T d e s}-0.40\right)-\psi_{\text {Tdes }}\right) \frac{\Phi_{c r}}{\Phi_{d e s}}}\right]
$$

An approximate value of the flow coefficient at the design flow rate. The approximate value $\varepsilon_{2} \approx 1.18$ is characteristic for the process compressor impellers:

$$
\varphi_{2 d e s}=\frac{\Phi_{\text {des }}}{4 \varepsilon_{2} \bar{b}_{2}} \approx \frac{\Phi_{\text {des }}}{4 \cdot 1.18 \cdot \bar{b}_{2}}
$$

If, at $\bar{b}_{3}=\bar{b}_{2}$ the angle $\alpha_{2 c r}$ is greater than the minimal angle $\alpha_{3 \min }$ or equal to it, the VLD with $\bar{b}_{3}=\bar{b}_{2}$ is the 
best solution.

$$
\begin{aligned}
& \text { If } \alpha_{2 c r<} \alpha_{3 \min }, \text { then the ratio } \bar{b}_{3} / \bar{b}_{2} \text { should be determined at which these angles are equal. Meaning that } \\
& \operatorname{tg} \alpha_{3 \min } \approx \operatorname{tg} \alpha_{2 c r} \frac{\bar{b}_{2}}{\bar{b}_{3}} \text { in accordance with formula (3), the equation resolves the problem: } \\
& \bar{b}_{3}=\frac{-0.0875+\sqrt{0.00766+14 \operatorname{tg} \alpha_{2 c r} \bar{b}_{2}}}{7}
\end{aligned}
$$

\section{VANELESS DIFFUSERS OF STAGES WITH DIFFERENT DESIGN PARAMETERS}

By the preliminary design method [27, 32, 33], the flow path dimensions of 18 stages were calculated. The range of design parameters $\Phi_{\text {des }}=0.15-0.015, \psi_{\text {Tdes }}=0.45-0.70$. The gas-dynamic characteristics were calculated by the Universal modeling method $[2,4,23,28]$ without "finishing" operations. An example of the characteristics is shown in Figure 10.

In the usual process of complete gas dynamic design by the Universal modeling method, the dimensions are corrected and the efficiency can be increased. For the present analysis of vaneless diffusers, the final design is not necessary. Some of the calculated parameters are presented in Table 1.

with $\Phi_{\text {des }}=0.15-0.015, \psi_{\text {Tdes }}=0.45-0.70$ and of theirs's VLD, $M_{u}=0,70$

- column \#3 - stage efficiency is calculated by the simplified model [27, 32, 33],

- column \#4 - according to the formula for the preliminary design of the impeller (not shown in the text),

- column \#5 - according to the formula for the preliminary design of the VLD, equation (15),

- column \#8 - $\Phi_{c r}(\mathrm{PD})$ is calculated according to equation (10) of the preliminary design,

- column \#9 - columns \#8/\#1.

The other parameters in Table 1 are taken from the calculation of the gas dynamic characteristics by the Universal modeling method.

The calculation results from Table 1 are presented graphically. In Figure 11, the height of the blades at the impeller exit are compared with the width of the VLD by preliminary design.

The algorithm for calculating the height of the impeller blades does not take into account the role of the loading factor. In the process of the final design, the value ${ }^{\bar{b}_{2}}$ is sometimes corrected. This does not affect the value ${ }^{\bar{b}_{3}}$. Within the range $\Phi_{\text {des }}=0.15-0.045$, the VLD width by preliminary design is practically proportional to the design flow rate. With the same $\Phi_{\text {des }}$ and larger loading factor, the flow angle in VLD is smaller. However, it turns out that at larger $\psi_{\text {Tdes }}$, the vaneless diffuser should be wider. The reason of the opposite is that the surge limit for impellers with bigger $\psi_{\text {Tdes }}$ is closer 
to the design flow rate - column \#9 Table 1.

In low-flow stages, flow separation in the VLD occurs at low flow angles, or does not occur at all. Slight VLD narrowing required in this case. High-flow stages have very large flow angles at the impeller exit. There is no need to increase them significantly in the diffusé.

The opposite situation takes place for medium flow rate stages. There the need for tapering of the VLD is maximal. Figure 12 shows the flow angles at the impeller exit and at the VLD main section inlet.

Stages with small loading factor at $\Phi_{\text {des }}>0.025$ have very large flow angles in the VLD. This is because such stages have a surge limit coefficient $\Phi_{c r} / \Phi_{d e s}=0.5-0.45$ [21] - and column \#9 Table 1. I is necessary to ensure nonseparated flow in the VLD at the surge limit. For stages with medium and high loading factors, the surge limit is closer to the design flow rate. Therefore, their VLD can be wider. In the final design, the choice of the VLD width can be significantly changed. For example, the first stage of a multistage compressor operates in a relatively narrow range of flow rates $\Phi_{c r} / \Phi_{d e s}<1$, which is limited by surge in the final stages [8].

Figure 13 shows in blue the minimum angle ${ }^{\alpha_{3 \min }}$ at which there is no separation in the VLD. The red color shows the angle $\alpha_{3 c r}$ that is calculated by exact mathematical model at the flow rate coefficient $\Phi_{c r}$.

In principle, these angles would have to coincide. However, in all cases in Figure 13, the value of the angle $\alpha_{3 \min }=\alpha_{3 c r}$ calculated by equation (13) is less than the value $\alpha_{3 c r}$ calculated by the mathematical model. The main reason is that in the


or not taken into account at all (equation (11)). The calculations of the characteristics in Table 1 are made at the impeller Mach number $M_{u}=0.70$. At the other $M_{u}$ the ratio of the angles $\alpha_{3 c r}$ and $\alpha_{3 \min }$ could be different.

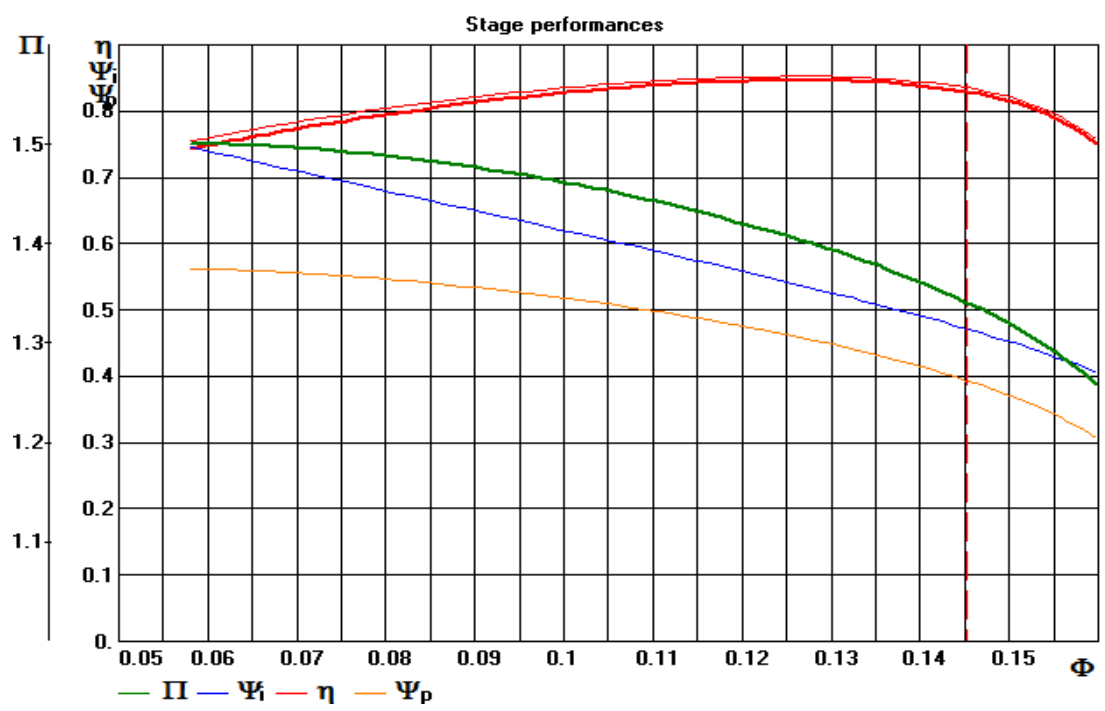

Figure 10: Stage Characteristics with $\Phi_{d e s}=\mathbf{0 . 1 5}, \psi_{\text {Tdes }}=\mathbf{0 . 4 5}$ with the 
Dimensions of the Flow Path According To The Preliminary Design.

Table 1: Some Parameters of the Stages

\begin{tabular}{|c|c|c|c|c|c|c|c|c|c|c|}
\hline $\mathbf{1}$ & $\mathbf{2}$ & $\mathbf{3}$ & $\mathbf{4}$ & $\mathbf{5}$ & $\mathbf{6}$ & $\mathbf{7}$ & $\mathbf{8}$ & $\mathbf{9}$ & $\mathbf{1 0}$ & $\mathbf{1 1}$ \\
\hline$\Phi_{\text {des }}$ & $\psi_{\text {Tdes }}$ & $\eta_{\text {des }}(\mathbf{P D})$ & $\bar{b}_{2}$ & $\bar{b}_{3}$ & $\alpha_{2 \text { des }}$ & $\alpha_{3 \text { des }}$ & $\Phi_{\text {cr }}(\mathbf{P D})$ & $\Phi_{c r} \Phi_{\text {des }}$ & $\begin{array}{c}\alpha_{3 \min } \\
(\mathbf{P D})\end{array}$ & $\begin{array}{c}\alpha_{3 c r} \\
(\mathbf{M M})\end{array}$ \\
\hline 0.15 & 0.45 & 0.8098 & 0.0852 & 0.0675 & 39.5 & 47.7 & 0.0752 & 0.501 & 17.9 & 18.9 \\
\hline & 0.575 & 0.818 & 0.0852 & 0.074 & 32.8 & 37.2 & 0.1037 & 0.691 & 19.1 & 23.8 \\
\hline & 0.70 & 0.817 & 0.0852 & 0.0775 & 27.6 & 30.3 & 0.1232 & 0.821 & 19.7 & 24.5 \\
\hline 0.10 & 0.45 & 0.846 & 0.0776 & 0.0466 & 31.6 & 47.2 & 0.0446 & 0.446 & 14.1 & 15.5 \\
\hline & 0.575 & 0.851 & 0.0776 & 0.0543 & 25.1 & 34.7 & 0.0659 & 0.659 & 15.5 & 20 \\
\hline & 0.70 & 0.85 & 0.0776 & 0.0588 & 21.6 & 27.9 & 0.0802 & 0.802 & 16.3 & 21.9 \\
\hline 0.070 & 0.45 & 0.854 & 0.0723 & 0.0348 & 24.4 & 45.4 & 0.0302 & 0.431 & 11.8 & 14.5 \\
\hline & 0.575 & 0.858 & 0.0723 & 0.0423 & 19.3 & 32.3 & 0.0455 & 0.650 & 13.3 & 18.3 \\
\hline & 0.70 & 0.856 & 0.0723 & 0.0467 & 16.0 & 25.1 & 0.0559 & 0.799 & 14.1 & 18.8 \\
\hline 0.045 & 0.45 & 0.845 & 0.0597 & 0.0256 & 19.5 & 40.9 & 0.0201 & 0.467 & 10.0 & 12.5 \\
\hline & 0.575 & 0.848 & 0.0597 & 0.0321 & 15.1 & 27.6 & 0.0298 & 0.662 & 11.3 & 15.5 \\
\hline & 0.70 & 0.845 & 0.0597 & 0.0357 & 12.2 & 20.6 & 0.0362 & 0.782 & 12.0 & 15.8 \\
\hline 0.030 & 0.45 & 0.801 & 0.04 & 0.0227 & 19.0 & 32.2 & 0.0154 & 0.513 & 9.5 & 11.6 \\
\hline & 0.575 & 0.802 & 0.044 & 0.027 & 13.7 & 22.1 & 0.0211 & 0.703 & 10.3 & 13.2 \\
\hline & 0.70 & 0.797 & 0.0482 & 0.0291 & 10.1 & 17 & 0.0249 & 0.83 & 10.7 & 13.4 \\
\hline 0.015 & 0.45 & 0.681 & 0.026 & 0.0176 & 15.6 & 22.9 & 0.0092 & 0.613 & 8.5 & 9.97 \\
\hline & 0.575 & 0.68 & 0.024 & 0.0193 & 12.7 & 15.8 & 0.0115 & 0.767 & 8.8 & 10.4 \\
\hline & 0.70 & 0.668 & 0.023 & 0.0198 & 10.6 & 12.6 & 0.0130 & 0.867 & 8.9 & 10.4 \\
\hline
\end{tabular}

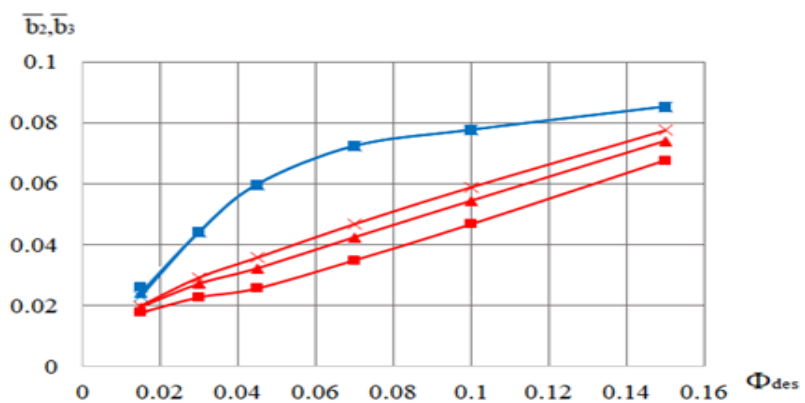

Figure 11: Relative Exit Height of the Blades (Blue)

And The Relative Width of the VLD (Red). ${ }^{\psi_{\text {Tdes }}=}$

0.45 (Square), ${ }^{\psi_{\text {Tdes }}=\mathbf{0 . 5 7 5} \text { (Triangle), }}{ }^{\psi_{\text {Tdes }}=\mathbf{0 . 7 0}}$ (Cross).



Figure 12: Flow Angles at the Impeller Exit and at the VLD Inlet. 
Blue - $\alpha_{2 d e s}$, red $-\alpha_{3 d e s} . \psi_{\text {Tdes }}=0.45$ (square), ${ }_{\text {Tdes }}=0.575$ (triangle), ${ }_{\text {Tdes }}=0.70$ (cross)

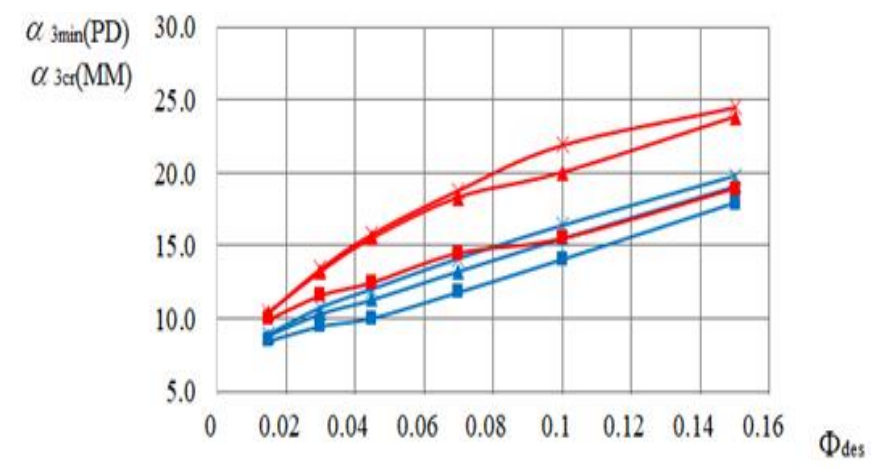

Figure 13: Flow Angles at the VLD Main Section

Entrance. Blue - $\alpha_{3 \min }$, Red - $\alpha_{3 c r}$

\section{CONCLUSIONS}

The proposed preliminary calculation of the rational width of the VLD is based on simplifying assumptions. In the given examples of accurate calculation by the Universal modeling method of flow angles at the impeller exit, it is shown that the rational width of the VLD can be greater than according to the primary calculation. It is also obvious that the accepted condition is not necessary in all cases. For example, in a multistage compressor, the first stage may have a surge limit coefficient significantly less than 1 , but not ever operate at a large distance from the design mode due to early surge in the final stages. Nevertheless, as part of the Universal modeling method, the proposed procedure for the primary design of VLD has shown its usefulness.

\section{ACKNOWLEDGEMENTS}

The study was funded by a grant from the Russian Science Foundation (project No. 18-79-10165).

\section{REFERENCES}

1. Galerkin, Yu. B. 2016. Alternative method for calculating the loading factor characteristics of a centrifugal compressor impeller. [text] / Yu. B. Galerkin, A. F. Rekstin, K. V. Soldatova, A. A. Drozdov // Compressor technic and Pneumatics. - 2016. - № 6. Pp. 1119.

2. Galerkin, Yu. B. 2004. Issues of flow path designing of natural gas centrifugal compressors. "Compressor technic and Pneumatics in the XXI century", vol. 2, Proceedings of the International scientific and technical conference on compressor engineering, September 15-17, 2004. Ukraine, Sumy, Publishing House of Sumy State University. - Pp. 166188.

3. Galerkin, Yu. B. 2011. Modeling of the working process of industrial centrifugal compressors. Scientific bases, stages of development, current state. / Yu. B. Galerkin, K. V. Soldatova // Saint Petersburg: Polytechnic University Publishing house, 2011.-328 p.

4. Galerkin, Yu. B. 2016. Principles of modeling the loading factor characteristics of a centrifugal impeller. [text]/Y. B. Galerkin, K. V. Soldatova //Compressor technic and Pneumatics, 2016, no. 1, Pp. 2434.

5. Galerkin, Yu. B. 2017. Development of the scientific school of turbocompressor engineering of LPI-SPbPU Peter the Great, results of cooperation with compressor engineers [text] / Yu.B. Galerkin, A. F. Rekstin, K. V. Soldatova, A. A. Drozdov, Yu. A. Popov // 17 international scientific and technical conference. - Kazan. - 2017. - May. - Pp. 1929. 
6. Galerkin, Yu. B. Improvement of vaneless diffuser calculations based on CFD experiment. Part 1 / Yu. B. Galerkin, O. A. Solovyova // Compressor technic and Pneumatics. - 2014. - no. 3. - Pp. 3541.

7. Galerkin, Yu. B. Improvement of vaneless diffuser calculations based on CFD experiment. Part 2 / Yu. B. Galerkin, O. A. Solovyova // Compressor equipment and Pneumatics. - 2014. - № 4. - P. 1521.

8. Galerkin, Yu. B. Turbocompressors. Workflow, calculation and design of the flow path. [text] / Yu. B. Galerkin // Information and publishing center KHT. - 2010. P. 596 p.

9. Galerkin Yu. B., Rekstin A. F., Solovieva O. A. 2019. Vaneless diffuser of the centrifugal compressor stage: sizes, calculation at the primary design. - News of higher educational institutions. - \#10(715)/2019-Moscow, MSTU. Bauman - 2019. - DOI: 10.18698 / 0536-1044-2019-10-43-57.

10. Den, G. N. Flow mechanics in centrifugal compressors / G. N. Den //Leningrad: Mashinostroenie, 1973. - P. 269.

11. Den, G. N. Flow path design of centrifugal compressors [text] /G. N. Den//Leningrad: Mashinostroenie: Leningrad Department, 1980. - P. 230

12. Kampsti, N. Aerodynamics of compressors: Transl. from s Engl. M.: Mir, 2000.688 p.

13. Livshits, S. p. Aerodynamics of centrifugal compressor machines /S. P. Livshits. - Moscow; Leningrad: Mashinostroenie, 1966. $340 \mathrm{p}$.

14. Nuzhdin, A. S. Investigation of flow in vaneless diffusers. [text] // Dis... Cand. tech. sci. - LPI. L.-1969.

15. Riess V. F. Centrifugal compressor machines. - Leningrad: Mashgiz, 1951. - 245 p.

16. Riess, V. F. Centrifugal compressor machines. [text] / V. F. Riess // - L.: Mashinostroenie. - 1964. - P. 336.

17. Riess, V. F. Centrifugal compressor machines [text] /V. F. Riess // - L.: Mashinostroenie, 1981.-351 p.

18. Seleznev, K. P. Centrifugal compressors. [text]/K. P. Seleznev, Yu. B. Galerkin // L.: Mashinostroenie. - 1982. P. 271.

19. Seleznev K. P., Galerkin Yu. B., Nuzhdin A. S., Strizhak L. Ya., Suslina I. P. Improving the efficiency of centrifugal compressor stages with vaneless diffusers. "Compressor and vacuum machines". - No. 2. - 1968 TSINTI-Himneftemash.

20. Seleznev K. P., Galerkin Yu. B., Nuzhdin A. S. Influence of the vaneless diffuser profile shape on the efficiency of the centrifugal compressor stage. Proceedings of the II conference on compressor engineering "Budivelnik" Niitehmash "Research in the field of compressor machines". - Kiev. 1970.

21. Soldatova, K. V. Creating a new mathematical model of the flow path of centrifugal compressors and a database of model stages: Dis.... doc. sci. science: 05.04.06/Soldatova K. V.; Saint Petersburg state Polytechnic University. - Saint Petersburg, 2017. 357 $p$.

22. Solovyeva, O. A. 2017. The dimensions' optimal ratios selection of low flow rate centrifugal compressor stage vaneless diffuser. / O. A. Solovyova, Yu. B. Galerkin // Compressor Technic and Pneumatics. - 2017. - no. 5. - Pp. 1115.

23. Solovyeva O. A. Galerkin Yu. B. Low flow rate centrifugal compressor stage vaneless diffuser analysis. Compressor Technic and Pneumatics. - 2017. - no. 3. - P. 1013.

24. Proceedings of the scientific school of compressor engineering of SPbSTU [text] / edited by prof. Yu.B. Galerkin // - Moscow: Publishing house " KHT"-2000.

25. Proceedings of the scientific school of compressor engineering of SPbGPU [text] / edited by Prof. Yu. B. Galerkin. - Moscow: publishing house "KHT"-2010. 
26. Aungier, Ronald H. Centrifugal compressors: a stragedy for aerodynamic design and analysis / Ronald H. Aungier // New York. - ASME Press. - 2000 / - P.320

27. Drozdov A., Rekstin A. Analysis of the velocity diagrams of impellers of centrifugal compressor stages after the preliminary design. - MATEC Web Conf. Volume 245, 2018. - International Scientific Conference on Energy, Environmental and Construction Engineering (EECE-2018). DOI 10.1051/matecconf/201824504004.

28. Galerkin, Y. 2015. New generation of Universal modeling for centrifugal compressors calculation. / Y. Galerkin, A. Drozdov // International Conference on Compressors and their Systems. London. City University. - UK. - 2015. - DOI: 10.1088/1757$899 \times / 90 / 1 / 012040$.

29. Jansen,W. Steady fluid flow in a radial vaneless diffuser. [text] / W. Jansen // Transactions ASME. - Journal of basic engineering. - Sept. -1964. - P. 607619.

30. Johnston, J.P. Losses in vaneless diffusers of centrifugal compressors and pumps. / J. P. Johnston, R. C. Dean // Trans ASME, Journal of Engineering for Power 88.-1966.

31. Rekstin, A.F. Two mathematical models centrifugal compressor stage vaneless diffuser comparison/A.F. Rekstin, A.A. Drozdov, O.A. Solovyeva, Yu.B. Galerkin // Oil and Gas Engineering (OGE-2018). -AIP Conf. Proc. 2007. - Omsk. - Russia. - 2018. 030035-1-030035-12; https://doi.org/10.1063/1.5051896.

32. Rekstin A.F., Galerkin Yu.B. 2019. The primary design method development of centrifugal compressor impellers based on the analysis of the geometrical parameters. - Oil and Gas Engineering- AIP Conf. Proc. 2141. - Omsk. - Russia. - 2019, 030052030052-10, https://doi.org/10.1063/1.5122102.

33. Rekstin A.F., Galerkin Yu.B., Soldatova K.V. 2019. Computer programs application for development a primary design recommendations of low-flow rate centrifugal compressor stages. - Oil and Gas Engineering- AIP Conf. Proc. 2141. - Omsk. Russia. - 2019, 030032-030032-10, https://doi.org/10.1063/1.5122082.

34. Sorokes, J.M. The Practical Application of CFD in the Design of Process Centrifugal Compressors [text] / J.M. Sorokes, B.R. Hutchinson // Challenges and Goals in Pipeline Compressors. PID.V. 5.-2000.

35. Sorokes, J.M. Sidestream optimization through the use of computational fluid dynamics and model testing [text] / J.M. Sorokes, D.A. Nye, N. D’Orsi, R. Broberg // Proceed. Texas: A\&M. - 2000. DOI:10.21423/R1QS8R.

36. Kotlov A.A., Maksimenko I.A. 2018. Mathematical modelling the seasonal load of opposite compressors. - Oil and Gas Engineering (OGE-2018). - AIP Conf. Proc. 2007. - Omsk. - Russia. - 2018. 030053-1-030053-9; https://doi.org/10.1063/1.5051914

37. Kotlov A.A. A reciprocating compressor operation in a net with pulsating pressure. - Oil and Gas Engineering (OGE-2018). AIP Conf. Proc. 2007. - Omsk. - Russia. - 2018. - 030038-1-030038-6; https://doi.org/10.1063/1.5051899.

38. Andrey Kotlov, Leonid Kuznetsov and Boris Hrustalev 2018. Influence of compressible medium on the operation of a reciprocating compressor. - MATEC Web Conf. Volume 245, 2018. - International Scientific Conference on Energy, Environmental and Construction Engineering (EECE-2018). DOI 10.1051/matecconf/201824504009

39. Kotlov A.A., Kuznetsov L.G., Burakov A.V. 2019. Analysis of reciprocating booster compressor performance by mathematical modelling methods. - Oil and Gas Engineering- AIP Conf. Proc. 2141. - Omsk. - Russia. - 2019, 030012-030012-9, https://doi.org/10.1063/1.5122062.

40. Kotlov A.A. 2019. Calculation and selection of parameters of the ring valve of reciprocating compressor. - Oil and Gas Engineering- AIP Conf. Proc. 2141. - Omsk. - Russia. - 2019, 030020-030020-10, https://doi.org/10.1063/1.5122070 
41. Kotlov A.A. 2019. Research of two-stage reciprocating compressor by methods of physical and mathematical experiments. - Oil and Gas Engineering- AIP Conf. Proc. 2141. - Omsk. - Russia. -2019, 030021-030021-10, https://doi.org/10.1063/1.5122071.

42. Kotlov, I. A. Maksimenko and Y. L. Kuznetsov. 2018. The influence of profile geometric parameters on characteristics of rotorgearing compressor. IOP Conf. Series: Materials Science and Engineering 425 (2018) 012012 doi:10.1088/1757$899 X / 425 / 1 / 012012$.

43. Kotlov. 2018. Influence of suction port parameters on integral characteristics of screw-type compressor. IOP Conf. Series: Materials Science and Engineering 425 (2018) 012014 doi:10.1088/1757-899X/425/1/012014.

44. Andrey Kotlov, Leonid Kuznetsov and Boris Hrustalev. 2018. Investigation of the influence of the number of vanes on the performance of a rotary vane compressor. - MATEC Web Conf. Volume 245, 2018. - International Scientific Conference on Energy, Environmental and Construction Engineering (EECE-2018). DOI 10.1051/matecconf/201824504008.

45. Kortikov N., Borovkov A., Voynov I., Kirillov A., Drozdov A. 2018. Modeling the gas-dynamic characteristics of the low-flow and mid-flow model stages for an industrial centrifugal compressor - MATEC Web Conf. Volume 245, 2018. - International Scientific Conference on Energy, Environmental and Construction Engineering (EECE-2018). DOI: https://doi.org/10.1051/matecconf/201824504019. 

